\title{
Produtividade e qualidade da flor-de-seda em diferentes densidades e sistemas de plantio ${ }^{1}$
}

\section{Maria Verônica Meira de Andrade ${ }^{2^{*}}$, Divan Soares da Silva ${ }^{3}$, Albericio Pereira de Andrade $^{3}$, Ariosvaldo Nunes de Medeiros ${ }^{3}$, Edgard Cavalcanti Pimenta Filho ${ }^{3}$, Magno José Duarte Cândido ${ }^{4}$, Maria do Socorro de Caldas Pinto ${ }^{5}$}

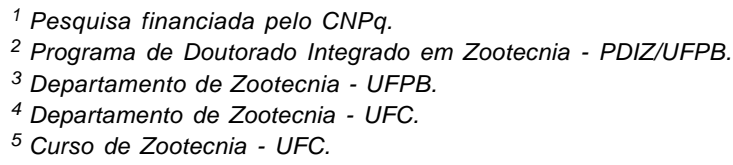

RESUMO - Avaliou-se o efeito de dois sistemas de plantio (sem camalhão e com camalhão) e de três espaçamentos $(1,0 \times 1,5 \mathrm{~m} ; 1,5 \times 2,0 \mathrm{~m}$; e 2,0 $\times 2,0 \mathrm{~m})$ sobre a qualidade e a produtividade de flor-de-seda aos 60 dias de rebrotação. Utilizou-se o delineamento experimental com blocos casualizados em esquema fatorial $2 \times 3$ (dois sistemas de manejo do solo e três densidades de plantio) com cinco repetições, em parcelas subdivididas no espaço e no tempo. Plantas escolhidas aleatoriamente foram cortadas, separadas por tratamento e analisadas quanto aos teores de matéria seca (MS), matéria orgânica (MO), cinzas, extrato etéreo (EE), proteína bruta (PB), fibra em detergente neutro (FDN), fibra em detergente ácido (FDA), celulose, hemicelulose, lignina, carboidratos não-fibrosos (CNF) e carboidratos totais (CT) e quanto à produtividade (kg MS/ha). Os sistemas de manejo do solo e as densidades de plantio não influenciaram a composição em MO, cinzas, FDN, EE, lignina, celulose, CNF e CT. As densidades de plantio influenciaram o teor de hemicelulose e FDA. O sistema de manejo do solo com camalhão teve efeito linear decrescente sobre o teor de PB. A maior produtividade de MS $(699,72 \mathrm{~kg} / \mathrm{ha})$ da flor-de-seda foi verificada no sistema de plantio mais adensado $(1,0 \mathrm{~m} \times 1,5 \mathrm{~m})$ e correspondeu a 6.666 plantas $/ \mathrm{ha}$.

Palavras-chave: Calotropis procera, forrageira nativa, manejo do solo, planta xerófila, semi-árido

\section{Productivity and quality of rooster tree in different planting densities and planting systems}

\begin{abstract}
The effect of two soil handling systems was evaluated (without furrow and with furrow), three spacing $(1.0 \mathrm{~m} \times 1.5 \mathrm{~m} ; 1.5 \mathrm{~m} \times 2.0 \mathrm{~m}$ and $2.0 \mathrm{~m} \times 2.0 \mathrm{~m})$ on the quality and the productivity of rooster tree 60 days after cut. It was used a split-plot (space and time) factorial arrangement in a randomized block design. Factors were two soil handling systems and three planting densities $(2 \times 3)$ with five replications per treatment. Plants chosen randomly were cut, separated in accordance with treatments and analyed the contents of dry matter (DM), organic matter (OM), mineral matter (MM), ether extract (EE), crude protein (CP), neutral detergent fiber (NDF), acid detergent fiber (ADF), cellulose, hemicellulose, lignin, water soluble carbohydrates (WSC), total carbohydrates (TC), and productivity (DM kg/ha). It was observed that the soil handling systems and planting densities did not influence the OM, MM, NDF, EE, lignin, cellulose, WSC and TC. The planting density affected the DM, hemicellulose, and ADF. The CP concentration was lower when using the handling systems with furrow. The DM largest productivity $(699.72 \mathrm{~kg} \mathrm{MS} / \mathrm{ha})$ of the rooster tree was verified in the more dense population $(1.0 \mathrm{~m} \times 1.5 \mathrm{~m})$, corresponding to 6,666 plants/ha.
\end{abstract}

Key Words: Calotropis procera, native forage, semi-arid zone, soil management, xerophytic plant

\section{Introdução}

A composição química pode ser utilizada como parâmetro de qualidade das espécies forrageiras, contudo, deve-se considerar que a composição depende de aspectos de natureza genética e ambiental e não deve ser utilizada como único determinante da qualidade de uma pastagem (Norton, 1981).
Segundo Van Soest (1994), elevadas temperaturas, característica marcante das condições tropicais, promovem rápida lignificação da parede celular, acelerando a atividade metabólica das células e resultando em decréscimo do pool de metabólitos primários no conteúdo celular, além de promover a rápida conversão dos produtos fotossintéticos em componentes da parede celular. Reduções

Este artigo foi recebido em 20/1/2006 e aprovado em 23/7/2007.

Correspondências devem ser enviadas para meiradeandrade@yahoo.com.br *Endereço atual: Rua Donatila Barreto/Apt ${ }^{\circ}$ G/ Areia-Paraíba/CEP: 58397-000. 
nas concentrações de lipídios, proteínas e carboidratos solúveis e aumento nas de carboidratos estruturais de maneira generalizada têm sido constatados nas espécies forrageiras, ocasionando redução sensível dos níveis de digestibilidade. De acordo com esse autor, o solo, o clima, o animal e as doenças influenciam o crescimento e a composição destas plantas forrageiras. Além disso, as plantas utilizam a energia solar para fixação de carbono em suas estruturas, mas a distribuição desse carbono e a energia fixada dentro da célula são amplamente afetadas por fatores externos ambientais. Deste modo, o valor nutritivo e a qualidade da forragem são consequiência desses fatores.

A Calotropis procera da família Asclepiadaceae, conhecida vulgarmente como flor-de-seda, leiteiro e queimadeira, tem se destacado entre as espécie adaptadas às condições semi-áridas. Tem ampla distribuição geográfica, especialmente em regiões tropicais e subtropicais de todo o mundo e na região semi-árida do Brasil, e nos últimos anos tem despertado atenção de pesquisadores interessados em sua utilização como forrageira.

Quanto à composição química, Abbas (1992) observou que a flor-de-seda é um arbusto sempre verde e abundante nas regiões áridas do Sudão e que possui aproximadamente $19,5 \%$ de PB em suas folhas, além de excelente digestibilidade da MS. Vaz et al. (1998) verificaram em fenos de flor-de-seda teores de $29,55 \%$ de FDN, $21,03 \%$ de FDA, $8,54 \%$ de hemicelulose, $11,13 \%$ de celulose e $21,23 \%$ de PB. Oliveira (2002) encontrou nesta mesma espécie percentuais iguais a 14,30; 14,00; 31,53 e 18,24\% de PB, cinzas, FDN e FDA, respectivamente.

Para obtenção de forragens de qualidade superior, é fundamental conhecer os efeitos dos diferentes fatores do meio para adotar práticas de manejo adequadas ao cultivo, principalmente em condições de déficit hídrico, como no Semi-Árido. Assim, aspectos como as características próprias da espécie, o estádio de desenvolvimento da planta e a idade de corte, além da influência de fatores ambientais como clima e solo, são decisivos para a qualidade da forragem (Heath et al., 1985).

O estádio de desenvolvimento da planta apresenta ampla relação com a composição química e a digestibilidade das forrageiras. Com o crescimento das forrageiras, ocorrem aumento nos teores de carboidratos estruturais e lignina e redução do conteúdo celular, o que, invariavelmente, proporciona redução da digestibilidade desses nutrientes.

Em trabalhos de pesquisa na EMPARN (2004), obteve-se produtividade de 1,0 t MS/ha/corte da flor-de-seda (Calotropis procera) aos 70 dias de rebrota cultivada em espaçamentos de $1,0 \times 0,5 \mathrm{~m}$ e $1,0 \times 1,0 \mathrm{~m}$. Constatou-se ainda que cortes posteriores realizados aos 120 dias de rebrota possibilitaram rendimentos de 3,0 t MS/ha/corte.

Uma vez que a obtenção de produtos animais em uma área de pasto é resultado da quantidade e qualidade de forragem produzida, tem-se buscado estratégias de cultivos de forrageiras que dêem sustentabilidade à pecuária nessa região. Assim, realizou-se este trabalho com o objetivo de avaliar a produtividade e a qualidade da flor-de-seda cultivada em diferentes densidades e sistema de plantio.

\section{Material e Métodos}

O trabalho foi realizado no município de Cubatí, microrregião do Curimataú paraibano. Pela classificação de Köppen (1936), o tipo climático da região é Bsh semi-árido quente, com chuvas de janeiro a abril, com precipitação média em torno de $400 \mathrm{~mm}$ anuais em condições climáticas normais, e temperatura média de $27^{\circ} \mathrm{C}$ (Figura 1).

Para caracterização físico-química do solo da área experimental, foram coletadas amostras na camada superficial do solo na profundidade de $20 \mathrm{~cm}$. As amostras foram conduzidas ao Laboratório de Análise de Solos e Água do CCA/UFPB. As determinações físicas e químicas (Tabela 1) constaram de granulometria, argila dispersa e grau de floculação, densidades do solo e de partículas, porosidade total (EMBRAPA, 1999) e água disponível no solo a 0,01 e a 1,5 $\mathrm{MPa}$, segundo metodologia proposta por Forsythe (1975). As determinações químicas constaram de $\mathrm{pH}$ em água, $\mathrm{P}, \mathrm{K}, \mathrm{Ca}, \mathrm{Mg}, \mathrm{Al}$ e $\mathrm{Na}$, segundo metodologia da EMBRAPA (1999).

As mudas de flor-de-seda foram preparadas utilizando-se sementes, no viveiro florestal no Departamento de Fitotecnia, Centro de Ciências Agrárias (CCA), da Universidade Federal da Paraíba - UFPB, em Areia, PB. As mudas foram transplantadas para o campo com aproximadamente 60 dias após a germinação.

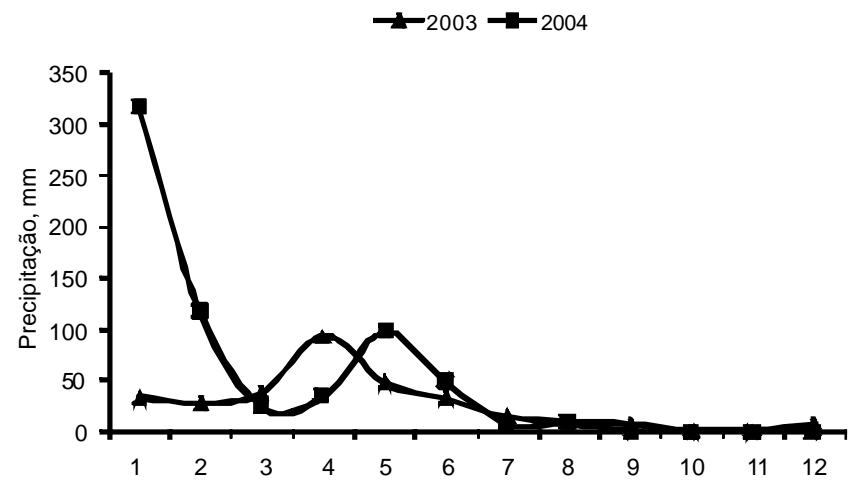

Figura 1 - Precipitação mensal nos anos de 2003 e 2004 no Município de Cubatí - PB. 
Tabela 1 - Características do solo da área experimental

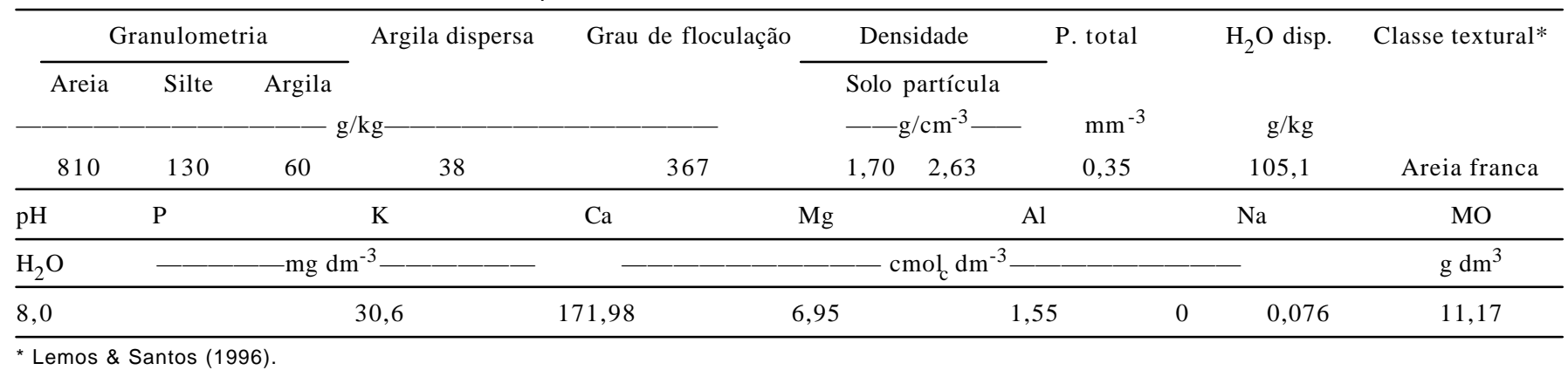

O plantio foi realizado no dia 30/4/2003, em covas de $20 \mathrm{~cm}$ de profundidade e em parcelas de $6,0 \times 6,0 \mathrm{mcom}$ 1,0 mentre cada parcela, de acordo com os espaçamentos. Utilizaram-se dois sistemas de preparo do solo, com e sem camalhão. O camalhão foi construído de forma transversal à declividade do terreno, com altura média de $40 \mathrm{~cm}$. Em ambos os sistemas, foram realizados a limpeza da área, o roço e o plantio das mudas nos espaçamentos estabelecidos. No sistema com camalhão, foram feitos leirões para plantio das mudas de flor-de-seda ao lado de cada camalhão. Após 30 dias do plantio, foram realizados em ambos os sistemas uma capina e um replantio e aplicado em cobertura $1,5 \mathrm{~kg}$ de esterco de ovino curtido por cova.

As densidades de plantio utilizadas foram de 6.666; 3.333 e 2.500 plantas por hectare nos espaçamentos $(1,0 \times$ $1,5 \mathrm{~m}, 1,5 \times 2,0 \mathrm{~m} \mathrm{e} 2,0 \times 2,0 \mathrm{~m}$ ), respectivamente.

A avaliação da qualidade e da produtividade da flor-deseda foi feita aos 60 dias de rebrota, ou seja, após o corte de uniformização a $40 \mathrm{~cm}$ de altura do nível do solo. Foram escolhidas três plantas por parcela para determinação da produtividade e da composição química, segundo o espaçamento e a densidade de plantio. Para a análise de composição química, as plantas foram cortadas e misturadas e, em seguida, foi retirada uma amostra de 400 a $500 \mathrm{~g}$. Todo o material foi levado ao Laboratório de Análise e Avaliação de Alimentos do CCA-UFPB para determinação da porcentagem de MS, EE, MO, cinzas, PB, FDN, FDA, lignina, celulose e hemicelulose, segundo metodologia descrita por Silva \& Queiroz (2002), carboidratos totais (CT) e solúveis (CHO), de acordo com metodologia de Sniffen et al. (1992). As fórmulas para calcular os carboidratos totais e os não-fibrosos foram: $\mathrm{CT}=100-(\% \mathrm{~PB}+\% \mathrm{EE}+\%$ Cinzas $)$ $\mathrm{e} \mathrm{CHO}=100-(\% \mathrm{FDN}+\% \mathrm{~PB}+\% \mathrm{EE}+\%$ Cinzas $)$.

O delineamento utilizado foi o de blocos casualizados, em arranjo fatorial $3 \times 2$, composto de três densidades de plantio $(1,0 \times 1,5 \mathrm{~m} ; 1,5 \times 2,0 \mathrm{~m} ; \mathrm{e} 2,0 \times 2,0 \mathrm{~m})$ e dois sistemas de preparo do solo (sem camalhão e com camalhão). Os dados foram submetidos a análises de variância e regressão pelo programa estatístico SAS.

\section{Resultados e Discussão}

Houve efeito linear crescente $(\mathrm{P}<0,05)$ da densidade de plantio, independentemente do sistema de plantio adotado, sobre a fitomassa da planta (Figura 2). Os valores médios de produtividade de MS da flor-de-seda foram 164,5; 199,94 e $699,72(\mathrm{~kg} / \mathrm{ha})$ no sistema de plantio sem camalhão (Figura 2) nas densidades de plantio de $2,0 \times 2,0 \mathrm{~m} ; 1,5 \times$ $2,0 \mathrm{~m} ; \mathrm{e} 1,0 \times 1,5 \mathrm{~m}$, respectivamente. No sistema de plantio com camalhão (Figura 2), os valores médios da produtividade da flor-de-seda foram 315,$61 ; 351,95$ e $533,36 \mathrm{~kg} / \mathrm{ha}$ nas mesmas densidades de plantio.

$\mathrm{Na}$ densidade de plantio de $1,0 \times 1,5 \mathrm{~m}$ (6.666 plantas/ ha), a produtividade da flor-de-seda foi superior em ambos os sistemas de plantio. No sistema sem camalhão, a produtividade da flor-de-seda foi $31,19 \%$ maior que no sistema com camalhão (Figura 2c). Entretanto, quando a densidade de plantas diminuiu para 3.333 e 2.500 plantas/ha, o acúmulo de MS tendeu a reduzir, efeito que foi menor no sistema de preparo com camalhão.

Em esquisas desenvolvidas pela EMPARN (2004) para avaliar a capacidade produtiva desta mesma planta cultivada em diferentes densidades de plantio aos 70 dias de rebrota, foram obtidos rendimentos de 1,0 t MS/ha/corte, nos espaçamentos de $1,0 \times 0,5 \mathrm{~m}$ e $1,0 \times 1,0 \mathrm{~m}$. Cortes posteriores, realizados aos 120 dias de rebrota, possibilitaram rendimentos de 3,0 t MS/ha/corte. As diferenças na produtividade podem estar relacionadas à idade de rebrotação da planta, à densidade de plantio e às condições edafoclimáticas.

Para o teor de PB da flor-de-seda, não houve efeito da interação densidade $\times$ sistema de plantio, ou seja, o efeito $(\mathrm{P}<0,05)$ da densidade de plantio e do sistema de manejo do solo sobre o teor de PB foi isolado, de modo que essas vairáveis apresentaram resposta linear decrescente (Figura 3). O teor de $\mathrm{PB}$ reduziu com o aumento da densidade de plantio no sistema de preparo do solo com camalhão (Figura 4). No entanto, não foi verificado efeito $(\mathrm{P}>0,05)$ do preparo do solo sem camalhão sobre o teor de $\mathrm{PB}$, independentemente 


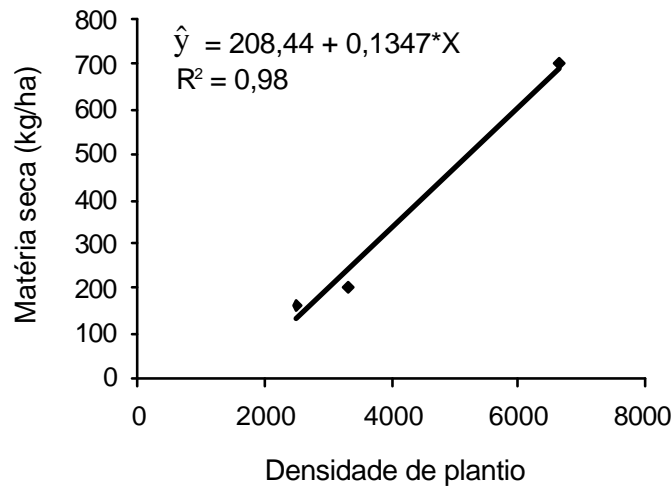

b

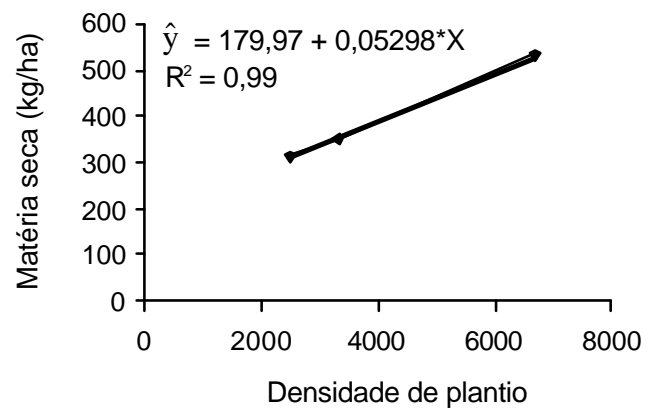

C

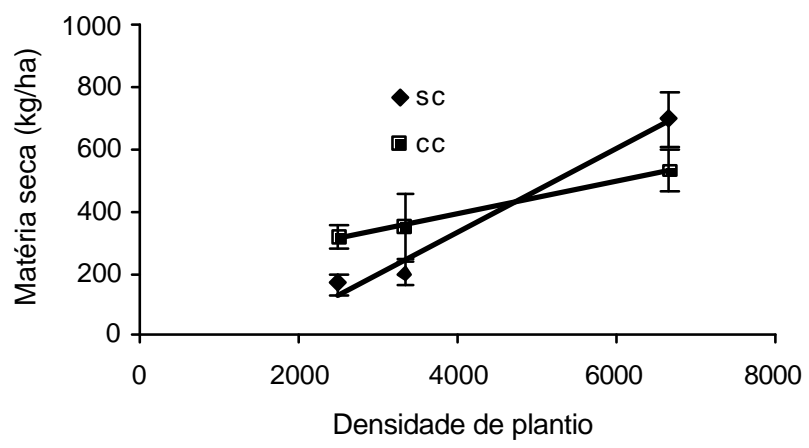

Figura 2 - Produtividade de matéria seca de flor-de-seda aos 60 dias de rebrota cultivada em diferentes densidades de plantio, em dois sistemas de plantio: a - sem camalhão (SC); b - com camalhão (CC) e c - dois sistemas de plantio.

da densidade de plantio. O valor médio de PB da flor-deseda, estimado pela equação de regressão, foi de $19,44 \%$ no sistema de plantio com camalhão, considerando todas as densidades de plantio.

$O$ teor PB tendeu a reduzir com o aumento da densidade de plantio (Figura 6) e esse efeito foi maior no sistema de preparo do solo com camalhão, o que pode estar associado ao fato de que, com o aumento da densidade de plantio, ocorre maior competição entre plantas, principalmente por água e nutrientes, uma vez que em densidade maior a demanda por nutrientes é mais acentuada.

O teor médio de PB $(19,4 \%)$ encontrado nesta pesquisa para flor-de-seda pode ser considerado bom em termos

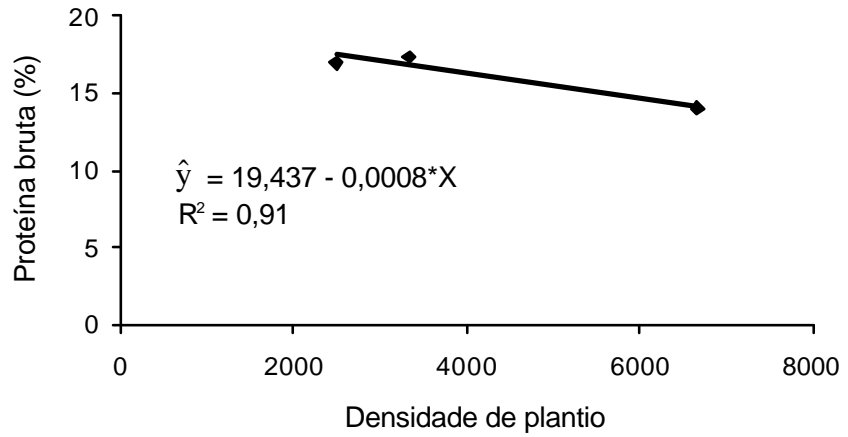

Figura 3 - Teor de proteína bruta de flor-de-seda aos 60 dias de rebrota cultivada em diferentes densidades e dois sistemas de plantio.

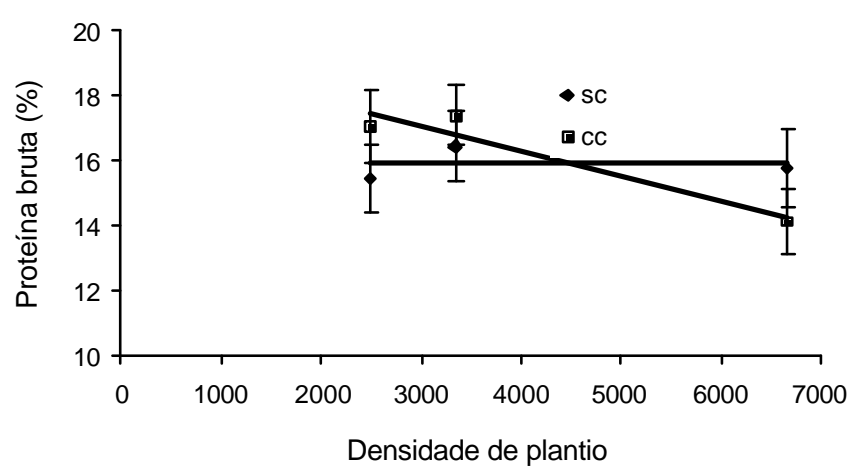

Figura 4 - Teor de proteína bruta de flor-de-seda aos 60 dias de rebrota cultivada em diferentes densidades e sistemas de plantio.

quantitativos, pois foram superiores aos valores recomendados para ruminantes. Essa espécie pode, portanto, ser promissora como forrageira, notadamente por sua adaptação às condições do Semi-Árido. Avaliando a composição bromatológica de várias plantas forrageiras tropicais, como feijão-bravo (Capparis flexuosa), moleque-duro (Cordia leucocephala), mela-bode (Desmodium adscendens) e malva-branca (Cassia uniflora), Nozella et al. (2001) encontraram 11,70 a 13,49\% de PB, teor bem abaixo do encontrado para flor-de-seda neste estudo.

Não houve efeito da interação densidade $\times$ sistema de plantio para o teor de FDA na planta. Verificou-se, no entanto, efeito linear crescente $(\mathrm{P}<0,05)$ das densidades de plantio (Figura 5). O valor médio estimado de FDA para a flor-de-seda pela equação de regressão foi de $28,48 \%$ para as densidades de plantio de $2.500(2,0 \times 2,0 \mathrm{~m}) ; 3.333(1,5 \times$ $2,0 \mathrm{~m})$ e $6.666(1,0 \times 1,5 \mathrm{~m})$ plantas/ha. Os valores médios de FDA foram semelhantes na densidade de plantio de 6.666 plantas/ha $(1,0 \times 1,5 \mathrm{~m})$, independentemente do sistema de plantio utilizado (Figura 6).

Os teores de FDA encontrados neste estudo foram inferiores aos obtidos por Nozella et al. (2001), de 34,69 a 
42,89\% na MS, em várias plantas forrageiras tropicais, como feijão-bravo (Capparis flexuosa), moleque-duro (Cordia leucocephala), mela-bode (Desmodium adscendes) e malvabranca (Cassia uniflora).

Para a variável hemicelulose, foi verificado efeito linear decrescente $(\mathrm{P}<0,05)$ das densidades de plantio (Figura 7$)$, no entanto, não houve efeito da interação densidade $\times$ sistema de plantio. O teor médio de hemicelulose da florde-seda estimado pela equação de regressão foi de $14,59 \%$, com redução de 0,0007 ponto percentual à medida que se aumentou o adensamento das plantas. Os resultados de hemicelulose foram semelhantes para a densidade de plantio de 6.666 plantas/ha $(1,0 \times 1,5 \mathrm{~m})$, independentemente do sistema de plantio adotado. Entretanto, apesar de o sistema de plantio não ter influenciado $(\mathrm{P}>0,05)$ o teor de hemicelulose, quando aumentou a densidade de plantas, houve tendência de redução na porcentagem de hemicelulose (Figura 8).

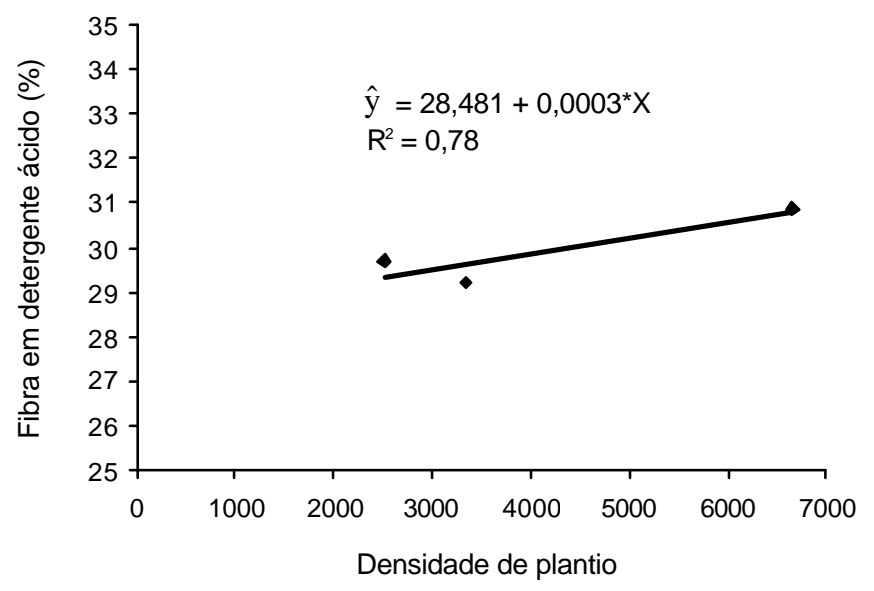

Figura 5 - Teor de fibra em detergente ácido de flor-de-seda aos 60 dias de rebrota cultivada em diferentes densidades de plantio.

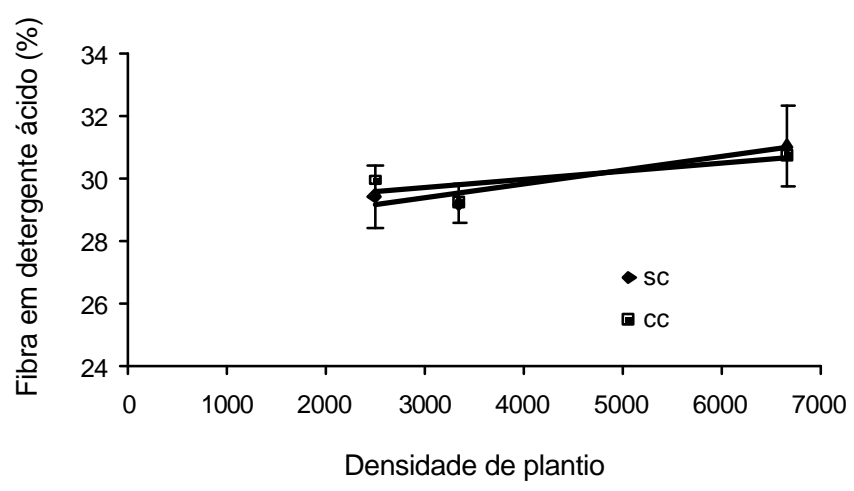

Figura 6 - Teor de fibra em detergente ácido de flor-de-seda aos 60 dias de rebrota cultivada em diferentes densidades e sistemas de plantio.
Não houve interação $(\mathrm{P}>0,05)$ densidade de plantio $\times$ sistema de manejo do solo para o teor de FDN da flor-deseda, que foi de $43,43 \%$ para o sistema de plantio sem camalhão nas densidades de plantio de $2.500(2,0 \times 2,0 \mathrm{~m})$; $3.333(1,5 \times 2,0 \mathrm{~m})$ e $6.666(1,0 \times 1,5 \mathrm{~m})$ plantas/ha, respectivamente. No sistema com camalhão, o teor médio de FDN da flor-de-seda foi de 40,91\% nas mesmas densidades de plantio (Figura 9a). Os valores médios de FDN foram semelhantes para a densidade de plantio de 6.666 plantas/ ha $(1,0 \times 1,5 \mathrm{~m})$, independentemente do sistema de plantio utilizado. Nas demais densidades de plantio, apesar de não ter havido efeito significativo, o teor de FDN aumentou quando se utilizou o sistema de manejo do solo sem camalhão.

A FDN compreende toda a parede celular, acrescida da hemicelulose, portanto, quanto maior a quantidade de fibra, menor o consumo de forragens pelo animal. Nozella et al. (2001), em pesquisa com outras espécies nativas,

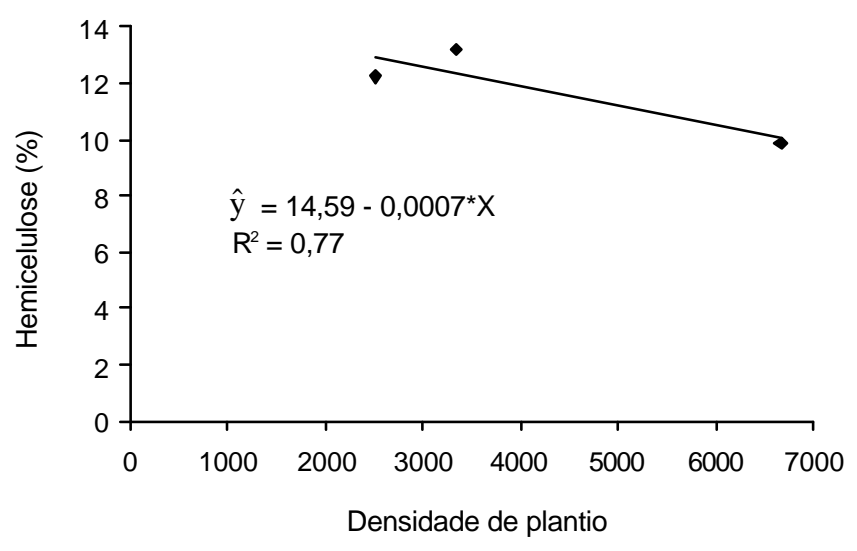

Figura 7 - Teor de hemicelulose de flor-de-seda aos 60 dias de rebrota cultivada em diferentes densidades de plantio.

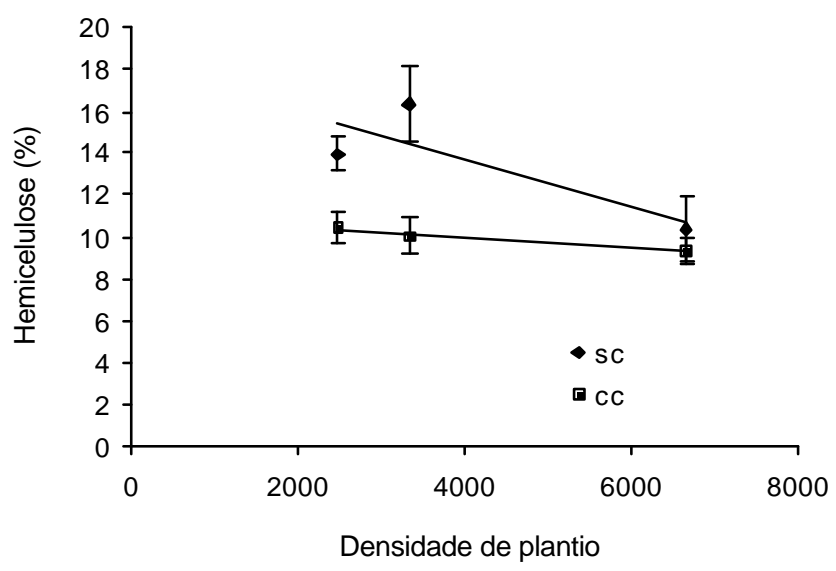

Figura 8 - Teor de hemicelulose de flor-de-seda aos 60 dias de rebrota cultivada em diferentes densidades e sistemas de plantio. 
encontraram teores médios na MS de 48,58 a 53,89\% de FDN, superiores aos encontrados para flor-de-seda neste trabalho.

Não houve efeito simples nem interação $(P>0,05)$ para o teor de matéria orgânica da flor-de-seda. Os valores médios foram semelhantes para todas as densidades de plantio testadas, independentemente do sistema de plantio utilizado. O valor médio obtido para o teor de matéria orgânica da flor-de-seda foi de $86,46 \%$ para o sistema de plantio sem camalhão. Para o sistema de plantio com camalhão, obteve-se o valor médio de $86,93 \%$ (Figura 9b).

Araújo et al. (1995), em experimento com feijão-bravo (Capparis flexuosa) em Serra Talhada, PE, encontraram valor médio de 89,46\% para o teor de MO. Araújo \& Brito (1998), avaliando a composição química de folhas e caule do mamãozinho-de-veado aos 150 dias, observaram teores médios de 68,69 e 77,60\% de MO, respectivamente.

Não houve efeito simples nem interação $(\mathrm{P}>0,05)$ para o teor de EE na flor-de-seda, uma vez que os valores médios foram semelhantes em todas as densidades de plantio testadas, independentemente do sistema de plantio utilizado. O resultado obtido para EE foi de 3,76\% no sistema de plantio sem camalhão e na densidade de plantio de 2.500 $(2,0 \times 2,0 \mathrm{~m}), 3.333(1,5 \times 2,0 \mathrm{~m})$ e $6.666(1,0 \times 1,5 \mathrm{~m})$ plantas/ha, respectivamente. No sistema de plantio com camalhão, o valor médio foi de 3,46\% para as mesmas densidades de plantio (Figura 9c).

Os valores de EE encontrados neste estudo corroboram os citados na literatura para as forrageiras maniçoba e catingueira, que apresentaram valores médios de 4,0 e 5,0\% da MS. Em trabalhos sobre a composição bromatológica de forrageiras arbustivas e subarbustivas nativas no estado da Bahia, Passos (1994) encontrou teores médios para EE de 1,$02 ; 2,85 ; 0,99 ; 2,66 ; 1,72$ e 2,42\% na MS para carquejo (Calliandra depauperata Benth), mata-pasto (Senna uniflora), quebra-facão (Croton mucronifoliuos), molequeduro (Cordia leucocephala), pau-de-acauã (Coursetia rostrata Benth) e umbuzeiro(Spondias tuberosa), respectivamente.

Não foi verificado efeito $(\mathrm{P}>0,05)$ simples e da interação para o teor de cinzas na planta. Os valores médios foram semelhantes para todas as densidades de plantio testadas, independentemente do sistema de plantio utilizado. O valor médio de cinzas foi de $13,74 \%$ no sistema de plantio sem camalhão nas densidades de plantio de $2.500(2,0 \times$ $2,0 \mathrm{~m}), 3.333(1,5 \times 2,0 \mathrm{~m})$ e $6.666(1,0 \times 1,5 \mathrm{~m}) \mathrm{plantas} / \mathrm{ha}$, respectivamente. No sistema de plantio com camalhão, o valor médio obtido foi $13,70 \%$ nas mesmas densidades de plantio (Figura 9d).
A partir do levantamento de plantas forrageiras arbóreas do sertão paraibano e sua composição bromatológica, Santos et al. (1990) encontraram em jurema-preta (Mimosa tennuiflora), catingueira (Caesalpinea pyramidalis), mororó (Bauhinia cheilantha) e marmeleiro (Croton sonderianus) teores médios de cinzas de 2,96; 4,14; 6,76; $7,34 \%$, respectivamente.

Não houve efeito $(\mathrm{P}>0,05)$ da densidade ou do sistema de plantio, nem da interação desses fatores, sobre o teor a celulose. O valor médio de celulose obtido na flor-de-seda foi de $21,16 \%$ para o sistema de plantio sem camalhão na densidade de plantio de $2.500(2,0 \times 2,0 \mathrm{~m}) ; 3.333(1,5 \times 2,0 \mathrm{~m})$ e $6.666(1,0 \times 1,5 \mathrm{~m})$ plantas/ha, respectivamente. No sistema de plantio com camalhão, o valor médio de celulose de florde-seda foi $19,34 \%$ para as mesmas densidades de plantio (Figura 9e). Os valores médios de celulose de flor-de-seda foram semelhantes para a densidade de plantio de 6.666 plantas/ha $(1,0 \times 1,5 \mathrm{~m})$, independentemente do sistema de plantio adotado. Entretanto, mesmo não tendo havido efeito significativo do sistema de plantio, quando se reduziu a densidade, houve tendência de aumento no percentual de celulose no sistema de plantio sem camalhão.

A densidade, o sistema de plantio e a interação densidade $\times$ sistema de plantio não tiveram efeito $(\mathrm{P}>0,05)$ sobre o teor de lignina na flor-de-seda. Foram observados valores próximos ao encontrados na literatura para volumosos forrageiros, ou seja, 9,0\%. Portanto, quanto menor a porcentagem desse constituinte, maior a digestibilidade do alimento caso não haja elemento antinutricional. O valor médio de lignina de flor-de-seda foi $9,31 \%$ para o sistema de plantio sem camalhão nas densidades de plantio de 2.500 $(2,0 \times 2,0 \mathrm{~m}), 3.333(1,5 \times 2,0 \mathrm{~m})$ e $6.666(1,0 \times 1,5 \mathrm{~m}) \mathrm{plantas} / \mathrm{ha}$, respectivamente. Para o sistema de plantio com camalhão, o valor médio foi 9,20\% para as mesmas densidades de plantio estudadas (Figura 9f).

Avaliando a composição bromatológica de forrageiras arbustivas e subarbustivas nativas no estado da Bahia, Passos (1994) encontrou teores médios de 5,82; 5,89; 21,42; 25,25; 2,02 e 6,17\% para lignina na MS, para as plantas de carquejo (Calliandra depauperata Benth), mata-pasto (Senna uniflora), quebra-facão (Croton mucronifoliuos), moleque-duro (Cordia leucocephala), pau-de-acauã (Coursetia rostrata Benth) e umbuzeiro (Spondias tuberosa), respectivamente.

O teor de carboidratos não-fibrosos não foi influenciado $(\mathrm{P}>0,05)$ pela densidade ou pelo sistema de plantio nem pela interação densidade $\times$ sistema de plantio. Os valores médios de CNFencontrados na flor-de-seda foram 23, 57; 27,07 e 24, $34 \%$ para o sistema de plantio sem camalhão nadensidade 
a

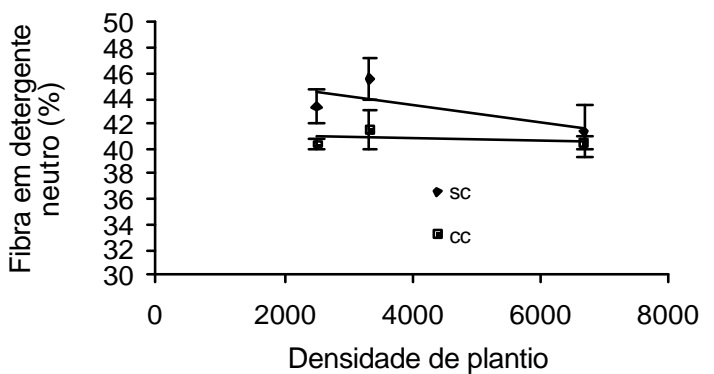

C

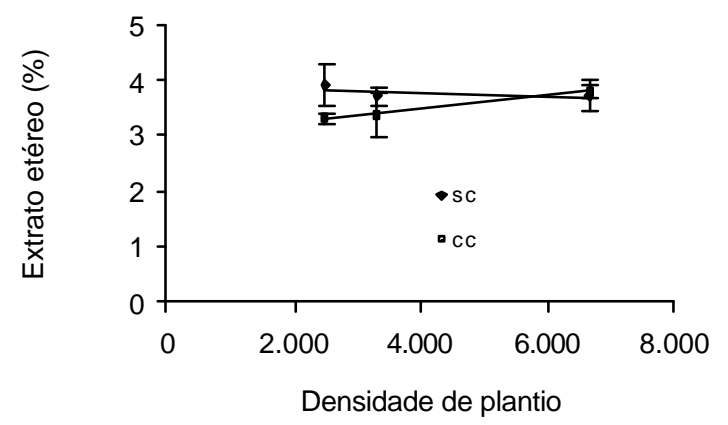

e

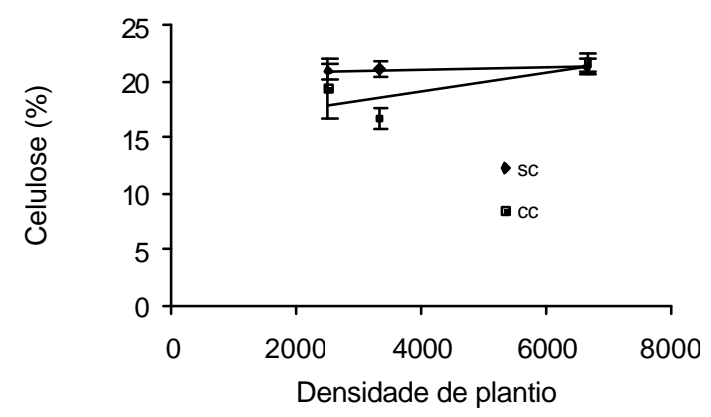

g

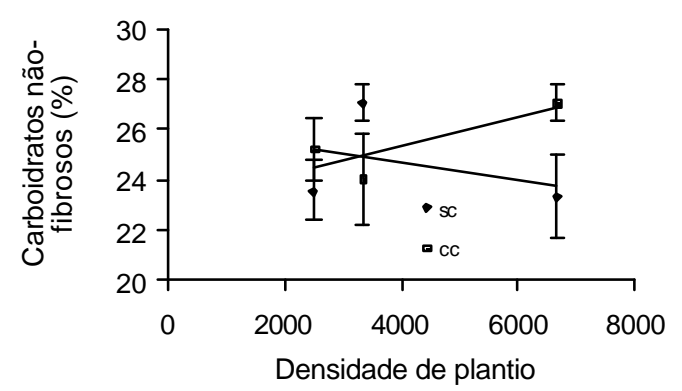

$\mathrm{b}$

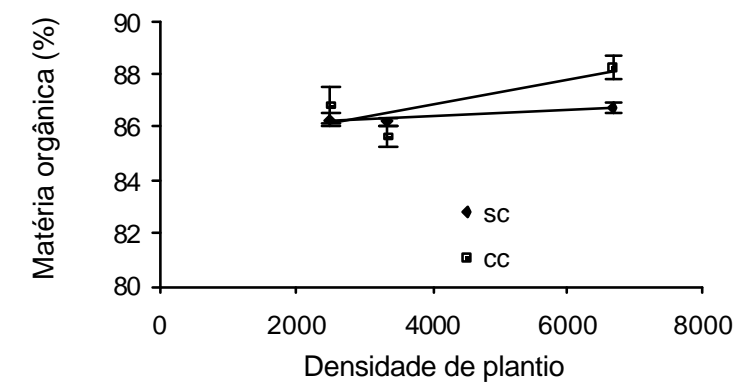

$d$
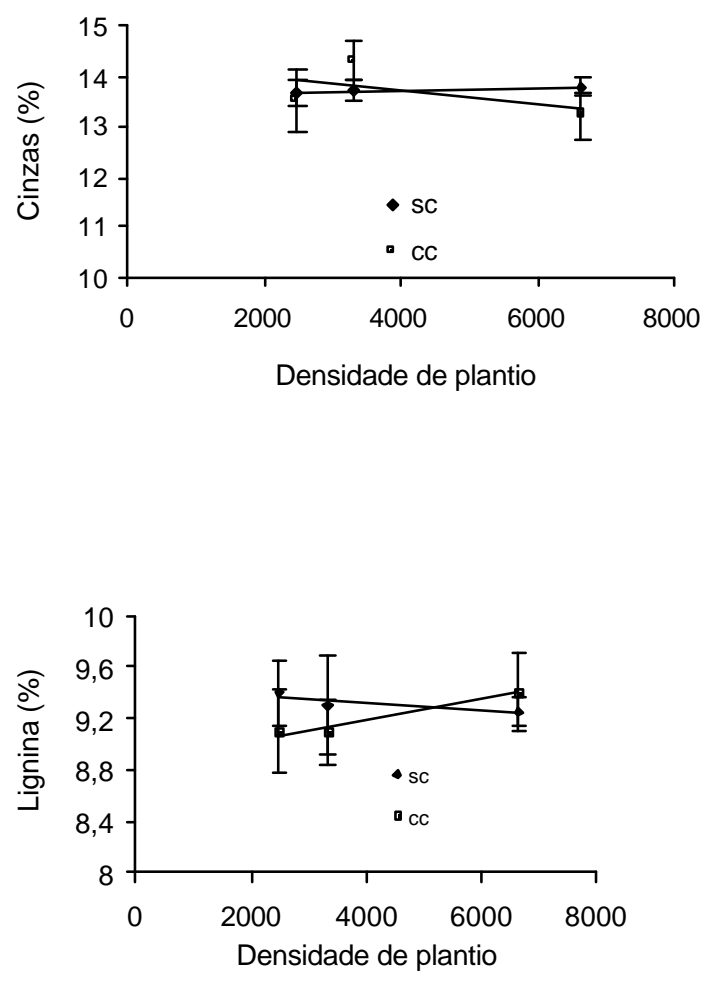

$\mathrm{h}$

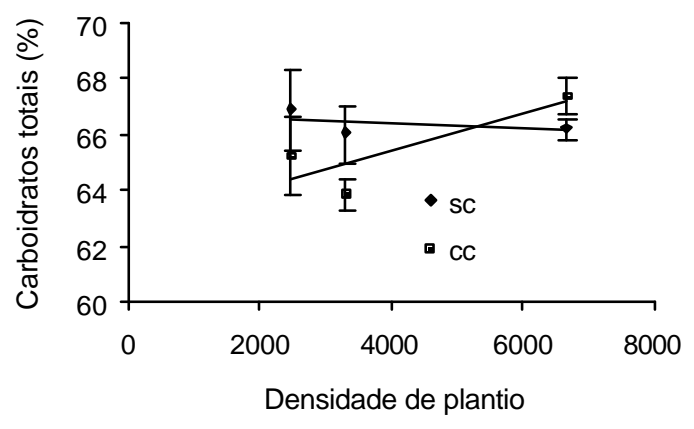

Figura 9 - Composição em fibra em detergente neutro (a), matéria orgânica (b), extrato etéreo (c), cinzas (d), celulose (e), lignina (f), carboidratos não-fibrosos (g) e carboidratos totais $(\mathrm{h})$ de flor-de-seda aos 60 dias de rebrota cultivada em diferentes densidades e sistemas de plantio. 
de plantio de $2.500(2,0 \times 2,0 \mathrm{~m}), 3.333(1,5 \times 2,0 \mathrm{~m})$ e $6.666(1,0$ $\times 1,5 \mathrm{~m})$ plantas/ha, respectivamente. No sistema de plantio com camalhão, os valores médios obtidos foram 25,25; 24,06 e $27,07 \%$ para as mesmas densidades de plantio (Figura 9g). Houve pequena variação nos teores de CNF da flor-de-seda nas densidades e nos sistemas de plantio testados.

Não foi verificado efeito $(\mathrm{P}>0,05)$ da densidade ou do sistema de plantio, nem dainteração densidade $\times$ sistema de plantio sobre a porcentagem de carboidratos totais na MS da flor-de-seda. Os valores médios obtidos foram 66,0 e $65,0 \%$ para os sistemas de plantio sem camalhão e com camalhão, respectivamente (Figura 9h). Os carboidratos são os principais constituintes das plantas forrageiras e correspondem de 50 a $80 \%$ de MS das forrageiras e cereais. Estes resultados são referentes a um corte, portanto, é fundamental proceder à análise criteriosa desses dados.

$\mathrm{O}$ acúmulo de MS e FDA aumentou $(\mathrm{P}<0,05)$ com a densidade de plantio; ao contrário, os teores de PB e hemicelulose diminuíram, independentemente do sistema de preparo do solo.

A composição química (MO, cinzas, FDN, EE, CNF, $\mathrm{CT}$, celulose e lignina) não foi influenciada $(\mathrm{P}>0,05)$ pelo sistema de preparo do solo. A densidade de plantio afetou $(\mathrm{P}<0,05)$ os teores de $\mathrm{PB}, \mathrm{FDA}$ e hemicelulose, mas não afetou $(\mathrm{P}>0,05)$ os teores de FDN, MO, EE, cinzas, CNF, CT, celulose e lignina.

\section{Conclusões}

A produtividade de matéria seca da flor-de-seda aumenta com densidade de plantio. Nas menores densidades de plantio (2.500 e 3.333 plantas/ha), o sistema de preparo do solo sem camalhão proporciona menor produtividade de matéria seca, que é maior no plantio mais adensado (6.666 plantas/ha). Os teores PB e hemicelulose reduzem com o aumento da densidade de plantio, ao contrário do teor fibra em detergente ácido, que aumenta. O sistema de preparo do solo não afeta a composição química de flor-deseda.

\section{Literatura Citada}

ABBAS, B.; EL-TAYEB.; SULLEIMAN, Y.R. Calotropis procera: feed potencial for arid zones. Veterinary-Record, v.131, n.6, p.132. ARAÚJO FILHO, J.A.; SILVA, N.L.; SOUSA, F.B. et al. Pastagens no semi-árido: pesquisa para o desenvolvimento sustentável.
In: REUNIÃO ANUAL DA SOCIEDADE BRASILEIRA DE ZOOTECNIA, 32., 1995, Brasília. Anais... Brasília: Sociedade Brasileira de Zootecnia, 1995. p.63-75.

ARAÚJO, G.G.L.; BRITO, N.C. Composição química da parte aérea e da raiz do mamãozinho-de-veado (Jacaratia corumbensis Kuntze) em diferentes idades. In: CONGRESSO NORDESTINO DE PRODUÇÃO ANIMAL, 1., 1998, Fortaleza. Anais... Sociedade Nordestina de Produção Animal, 1998. p.87.

EMPRESA BRASILEIRA DE PESQUISA AGROPECUÁRIAEMBRAPA. Sistema brasileiro de classificação de solos. Brasília: EMBRAPA/Solos, 1999. 412p.

EMPRESA DE PESQUISA AGROPECUÁRIA DO RIO GRANDE DO NORT E - EMPARN. Armazenamento de forragens para a agricultura familiar. Natal: 2004. 38p.

FORSYTHE, W.M. Física de suelos: manual de laboratório. San Jose: Instituto Interamericano de Ciências Agrícolas, 1975. p. 212 .

HEATH, M.E.; BARNES, R.F.; METCALFE, D.S. Forage - The science of grassland agriculture. Ames: 1985. 643p.

LEMOS, R.C.; SANTOS, R.D. Manual de descrição e coleta de solos no campo. 3.ed. Campinas: SBCS/CNPS, 1996. 84p.

KOPPEN. W. Dasa geographi SC system der klimate. In: KOPPEN. W.; GEIGER, R. (Eds.) Handbuch der klimatologia. Berlim: Gerdrulier Borntraeger, v.1. 1936. 44p.

NORTON, B.W. Differences between species in forage quality. In: HACKER, J.B. (Ed.) Nutritional limits to animal production from pastures. Farham Royal: CSIRO, 1981. p.89-110.

NOZELLA, E.F.; BUENO, I.C.S.; CABRAL FILHO, S.C.S. et al. Degradabilidade ruminal in situ de plantas contendo taninos em ovinos da raça Santa Inês. In: REUNIÃO ANUAL DA SOCIEDADE BRASILEIRA DE ZOOTECNIA, 38., 2001, Piracicaba. Anais... Sociedade Brasileira de Zootecnia, 2001. p.1242-1243.

OLIVEIRA, V.M. Estimativas da biomassa de Calotropis procera (Ait) R. Br., e determinação de sua composição química nos municípios de Patos e Santa Luzia - PB. Areia: Universidade Federal da Paraíba, 2002. 40p. Dissertação (Mestrado em Zootecnia) - Universidade Federal da Paraíba, 2002.

PASSOS, R.A.M. Análise química de forrageiras arbustivas e subarbustivas nativas da região nordeste do estado da Bahia. In: REUNIÃO ANUAL DA SOCIEDADE BRASILEIRA DE ZOOTECNIA, 31., 1994, Maringá. Anais... Maringá, 1994. p.302.

STATISTICAL ANALYSIS SYSTEM - SAS. Users' guide. Cary: 1997. (CD-ROM).

SANTOS, G.J.C.; SILVA, J.; SILVA, A.M.A. et al. Levantamento de forrageiras arbóreas do sertão paraibano e sua composição bromatológica. In: REUNIÃO ANUAL DA SOCIEDADE BRASILEIRA DE ZOOTECNIA, 27., 1990, Campinas. Anais... Campinas: Sociedade Brasileira de Zootecnia, 1990. p.308.

SILVA, D.J.; QUEIROZ, A.C. Análise de alimentos: métodos químicos e biológicos. Viçosa, MG: Editora UFV, 2002. 235p.

SNIFFEN, C.J.; O'CONNOR, J.D.; van SOEST, P.J. A net carbohydrate and protein system for evaluating cattle diets. Journal Animal Science, v.70, p.3562-3577, 1992.

Van SOEST, P.J. Nutritional ecology of the ruminant. New York: Cornell University Press, 1994. 476p.

VAZ, I.D.; LOGULLO, C.; SORGINE, M. et al. Immunization of bovines with an aspartic proteinase precursor isolated from Boophilus microplus eggs. Veterinary Immunology and Immunopathology, v.66, n.3-4, 331-341, 1998. 